\title{
Effects of Chemoreceptor Modification on the Structures of Tsr arrays
}

\author{
Rosemary S. McAndrew ${ }^{*, * * *}$, E. Ann Ellis ${ }^{* *}$, RunZhi Lai ${ }^{*}$, Michael Manson ${ }^{*, * * *}$, and Andreas \\ Holzenburg, ${ }^{* * * * * * *}$
}

*Department of Biology, ${ }^{* *}$ Microscopy and Imaging Center (MS 2257), and ${ }^{* * *}$ Department of
Biochemistry and Biophysics, Texas A\&M University, College Station, TX 77843-2257

Bacterial chemotaxis is mediated by a sensory complex that is localized to clusters at the cell poles and composed of a mixture of self-associating transmembrane receptors, primarily Tsr (receptors for serine), and the protein signaling proteins $\mathrm{CheW}$ and CheA [1]. A large body of evidence suggests that interactions among receptors are key signaling parameters and that arrays function in a highly cooperative manner, mimicking the behavior of allosteric proteins $[2,3]$. These receptors function as homodimers, bind ligands in the periplasm, and initiate signaling in the cytoplasm by coupling the autokinase activity of CheA to receptors through CheW. Modulation of kinase activity within arrays is poorly understood, but association of CheA with receptors may be strongly affected by receptor methylation. TEM has been used to investigate the structural characteristics of Tsr by examining their assemblies in native inner membranes of E. coli with or without $\mathrm{CheA}, \mathrm{CheW}$, and the attractant ligand serine $[4,5]$. Here, we investigate the structural effects of receptor modification on arrays formed by Tsr in fixed states of methylation.

Tsr receptors fixed in non-, half-, or fully-methyled states, EEEE, QEQE, or QQQQ, respectively, were expressed separately in E. coli strain RP3098 which lacks all chemotaxis proteins, recovered in inner membranes, and processed for TEM analysis, as previously described [5]. Immunolabeling of Tsr in thin cell sections and membranes, and assays for receptor-coupled CheA kinase activity confirmed Tsr expression and formation of active signaling complexes. Samples deposited on glowdischarged grids were negatively stained with $2 \%$ uranyl acetate and crystallographic image analysis was performed using the software package CRISP [6], as previously described.

TEM analysis of arrays formed by Tsr receptors in fixed methylation states suggests that the level of receptor methylation may influence the structural characteristics of receptor arrays (Fig. 1). In the non-methylated state, Tsr arrays were predominantly observed in clusters of rosettes [5], proposed trimers of dimers (Fig. 1A). Half-methylated Tsr arrays were observed both as rosettes and fixed 2D lattices (Fig. 1B). Fully-methylated Tsr arrays were predominantly observed in highly-ordered 2D crystalline arrays (lattice parameters, $a=b=8.2 \mathrm{~nm} ; \gamma=120^{\circ}$ ), similar to those reported previously [5]. These results, summarized in Table 1, provide new direct evidence that receptor modification may play a role in the proposed allosteric behavior of chemosensory complexes and contribute to our understanding of the molecular basis of transmembrane signaling pathways.

\section{References}

[1] M. D. Baker et al., BioEssays 28.1 (2005) 9.

[2] V. Sourjik, Trends Microbiol. 12 (2004) 569.

[3] R-Z. Lai et al., Biochemistry 44 (2005) 14298.

[4] J. Lefman et al., J. Bacteriol. 186 (2004) 5052. 
[5] R. S. McAndrew et al., Microsc. Microanal. 11 (Suppl. 2) (2005) 1190CD.

[6] S. Hovmoller, Ultramicroscopy 41 (1992) 121.

[7] This research was supported by NIH Grant RO1 GM39736-13 and the Program for Membrane Protein Structure and Function established by Texas A\&M University.
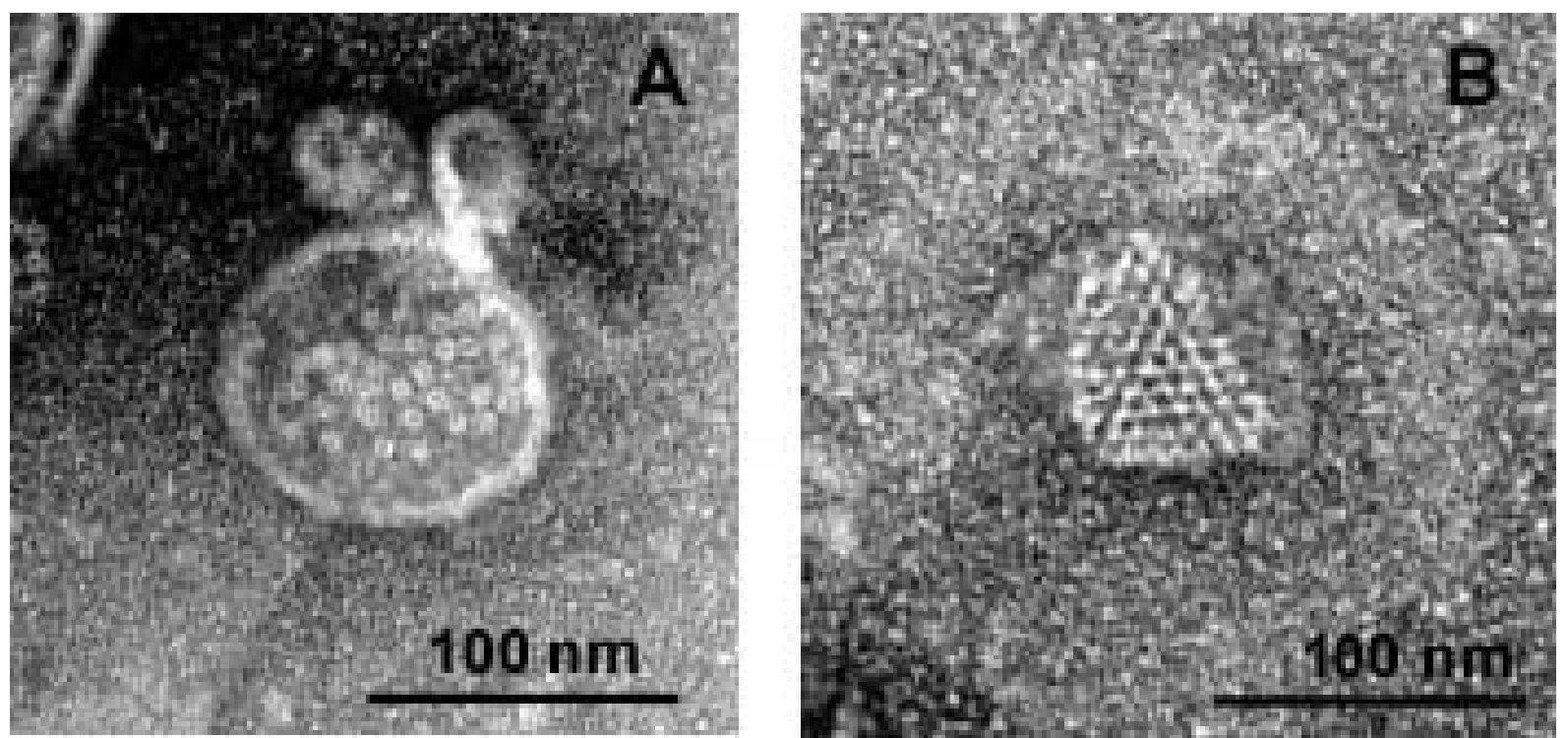

FIG. 1. Electron micrographs showing negatively stained $E$. coli inner membranes that contain receptors organized (A) as a cluster of rosettes (trimers of dimers) and (B) in an ordered twodimensional lattice that is the predominantly seen in Tsr arrays in the fully methylated state.

Table 1. Effects of attractant ligand binding and receptor modification on the structures of Tsr arrays formed in E. coli inner membranes

\begin{tabular}{|c|c|c|c|c|c|c|}
\hline $\begin{array}{l}\text { Level of } \\
\text { receptor } \\
\text { methylation }\end{array}$ & $\begin{array}{l}\text { Tsr } \\
\text { (alone) }\end{array}$ & $\begin{array}{l}\text { Tsr } \\
1 \mathrm{mM} \\
\text { serine }^{2}\end{array}$ & + & $\mathbf{T s r}+\mathbf{W}+\mathbf{A}^{3}$ & $\begin{array}{l}\text { Tsr+W+A } \\
+1 \mu M \\
\text { serine }^{4}\end{array}$ & $\begin{array}{l}T s r+W+A+ \\
1 \mathrm{mM} \text { serine }\end{array}$ \\
\hline $\begin{array}{l}\text { Tsr EEEE } \\
\text { (non-methylated) }\end{array}$ & $\mathbf{R}^{5}$ & ND-r ${ }^{6}$ & & ND-r & $\mathbf{R}+[\mathbf{l}]^{7}$ & ND $^{8}$ \\
\hline $\begin{array}{l}\text { Tsr QEQE } \\
\text { (half-methylated) }\end{array}$ & $\mathbf{R}+\mathbf{L}^{9}$ & $\mathbf{R}+\mathbf{L}$ & & $\mathbf{R}$ & $\mathbf{R}+\mathbf{L}$ & $\mathbf{R}$ \\
\hline $\begin{array}{l}\text { Tsr QQQQ } \\
\text { (fully-methylated) }\end{array}$ & $\mathbf{L}+\mathbf{R}$ & $\mathbf{L}+\mathbf{R}$ & & $\mathbf{L}$ & $\mathbf{L}+[\mathbf{r}]^{10}$ & $\mathbf{L}$ \\
\hline
\end{tabular}

${ }^{1}$ Inner membranes containing $6 \mu \mathrm{M} \mathrm{Tsr} ;{ }^{2}$ saturating levels of attractant ligand serine; ${ }^{3} \mathrm{Tsr}(6 \mu \mathrm{M})$, CheW $(3 \mu \mathrm{M})$, and CheA $(3 \mu \mathrm{M}) ;{ }^{4}$ subsaturating levels of serine; ${ }^{5} \mathrm{R}=$ prevalent clusters of rosettes (trimers of dimers); ${ }^{6} \mathrm{ND}-\mathrm{r}=$ mostly non-distinct features with very few rosettes; ${ }^{7}[1]=$ poorly structured lattices; ${ }^{8} \mathrm{ND}=$ membranes with non-distinct features; ${ }^{9} \mathrm{~L}=$ highly ordered fixed 2 -D lattices; ${ }^{10}[\mathrm{r}]=$ very few rosettes. 